\title{
Asymmetric price transmission within the Portuguese stock market
}

\author{
Rui Menezes ${ }^{\mathrm{a}}$, Andreia Dionisio,*, Diana A. Mendes ${ }^{\mathrm{a}}$ \\ ${ }^{a}$ ISCTE, Av. Forcas Armadas, 1649-025 Lisboa, Portugal \\ ${ }^{\mathrm{b}}$ Management Department, University of Evora, Largo Colegiais 2, Evora 7000, Portugal
}

Received 12 December 2003

Available online 20 July 2004

\begin{abstract}
This paper uses threshold autoregressive (TAR) and momentum threshold autoregressive (M-TAR) models to address the problem of asymmetry within the Portuguese stock market. These asymmetric error correction models extend the original cointegration models to deal with the problem of low power of unit roots and cointegration tests in the presence of asymmetric adjustment.
\end{abstract}

(C) 2004 Elsevier B.V. All rights reserved.

PACS: 89.90. $+\mathrm{n}$

Keywords: Asymmetric price transmission; Threshold adjustment; Cointegration

\section{Introduction}

The financial market is characterised by movements in the stock prices that typically depend on a number of factors, both exogenous and endogenous. These movements may be upwards or downwards in response to changes in the predictors. However, the magnitude of positive and negative responses may differ for similar positive and negative variations in the predictors, in which case we can say that the

\footnotetext{
*Corresponding author. Tel.: + 351-91-910-8039; fax: + 351-266-742494.

E-mail addresses: rui.menezes@iscte.pt (R. Menezes), andreia@uevora.pt (A. Dionisio).
} 